should be aware of such specific features as similar survival rates in cutaneous and ssSSc pts, and late recognition of $\mathrm{PAH}$ in pts with ssSSc, as well as its similarity with IPAH

Disclosure of Interest: None declared

DOI: 10.1136/annrheumdis-2018-eular.5517

\section{AB0792 AUTOIMMUNE AND INFLAMMATORY DISTURBANCES IN PATIENTS WITH PULMONARY ARTERIAL HYPERTENSION ASSOCIATED WITH SYSTEMIC SCLEROSIS}

N. Yudkina ${ }^{1}$, A. Volkov ${ }^{1}$, T. Martynyuk ${ }^{2}$, E. Nikolaeva ${ }^{1}$, E. Nasonov ${ }^{1} .{ }^{1}$ V.A. Nasonova Research Institute of Rheumatology, Moscow, Russia; ${ }^{2}$ Cardiology Scientific Medical Research Center, Moscow, Russian Federation

Background: The prognosis of patients with pulmonary arterial hypertension associated with systemic sclerosis (SSc-PAH) is significantly worse, than other forms of $\mathrm{PAH}$, and mechanisms of this phenomenon are unknown. Therefore, the isolation of autoimmune disorders is of great importance for early diagnosis and differential diagnosis, as well as the search for new therapeutic targets.

Objectives: To identify the autoimmune disorders in patients with SSc-PAH.

Methods: The study includes 52 pts with idiopathic pulmonary arterial hypertension (IPAH), 51 pts with SSc-PAH, 65 pts with SSc without PAH. Serum concentrations of the C-reactive protein (CRP), anticentromere antibodies (ACA) and antibodies to topoisomerase-I (anti-Scl-70) were routinely measured. The control group consists of 146 volunteers. Statistical analysis includes univariable logistic regression, $\mathrm{ROC}$ analysis and Kaplan-Mayer method.

Results: The average age of patients with IPAH was $37.9 \pm 10.5$ years, SSc-PAH $-52.3 \pm 12.7$ years, SSc without $\mathrm{PAH}-51.2 \pm 13.2$. Patients did not differ in functional class (FC), which was the main criterion of comparability. Mean values of $\mathrm{FC}$ in groups with SSc-PAH and IPAH also did not differ $(2.7 \pm 0.8$ and $2.6 \pm 0.7$, respectively). ACA was associated with a 15.2-fold increased odds of developing $\mathrm{PAH}$ in SSc (OR 15.2, 95\% CI 5.4-43.0), on the contrary, presense of anti-Scl-70 associated with low risk of PAH (OR $0.5,95 \% \mathrm{Cl} 0.01$ to 0.21$)$. The level of CRP in the serum was significantly higher in patients with $\mathrm{PAH}$ than in the control group: $4.1(1.9,10.0)$ and $0.61(0.25,1.9), p<0.000001$, and also in comparison with patients without PAH $(1.9(0.8,6.4), \mathrm{p}=0.02)$. In pts with $\mathrm{PAH}$, the level of $\mathrm{CRP}$ correlated with $\mathrm{FC}$ and right atrium pressure and 6 min walk test distance. The level of CRP was significantly higher in patients with FC III-IV compared with FC I-II and in non-surviving patients. The Kaplan-Mayer analysis showed that pts with CRP level more than $4.75 \mathrm{mg} / \mathrm{L}$ at the time of diagnosis of PAH had a significantly lower survival rate (median 48 months) than pts with normal values (median 91 months) $(\mathrm{p}<0.005)$, with $67 \%$ sensitivity and $61 \%$ specificity.

Conclusions: SSc-PAH is a unique phenotype combining the manifestations of SSc and PAH, the pathogenetic mechanisms of which modify the course of these states. It is based on a feature of autoimmunity with the predominance of ACA and a low occurrence of anti-Scl-70. An increase in the concentration of CRP, as well as the effect of its baseline level on survival, attests to the significant role of autoimmunity and inflammation in the pathogenesis of this fatal SSc complication.

Disclosure of Interest: None declared

DOI: 10.1136/annrheumdis-2018-eular.7170

\section{AB0793 DESCRIPTIVE ANALYSIS OF A COHORT OF PATIENTS DIAGNOSED WITH INFLAMMATORY MYOSITIS IN A TERTIARY HOSPITAL}

O. Ibarguengoitia ${ }^{1}$, E. Ruiz' ${ }^{1}$ M.L. García ${ }^{1}$, S. Kapetanovic ${ }^{2}$, O. Fernández¹, I. Torre ${ }^{1}$, A.R. Inchaurbe ${ }^{1}$, C. Pérez ${ }^{1}$, J.M. Blanco ${ }^{1}$, I. Calvo ${ }^{1}$, E. Guerrero ${ }^{1}$ D. Montero ${ }^{1}$, E. Galindez ${ }^{1} .{ }^{1}$ Rheumatology, ${ }^{2}$ Neurology, Basurto University Hospital, Bilbao, Spain

Background: Inflammatory myopathies are a group of rare systemic diseases characterised by muscle weakness and inflammation. Clinical manifestations, course and prognosis of these patologies are very heterogeneous.

Objectives: The aim is to describe the main characteristics of patients diagnosed with inflammatory myositis fulfilling Bohan and Peter criteria.

Methods: Descriptive analysis of a cohort of 34 patients from the same hospital with follow-up between January 2010 and December 2017. We recorded demographic characteristics, clinical manifestations, treatment, comorbidity and mortality.

Results: 34 patients (73\% female) were recruited with an average age at diagnosis of 56.3 years ${ }^{27-83}$ among adults and 10 years ${ }^{4-15}$ among children. Most of them were Caucasian (94\%). 18\% were smokers and $15 \%$ previous smokers. The most frequent type was dermatomyositis (DM) (40\%) followed by antisynthetase syndrome (ASS) (15\%), necrotizing myopathy (12\%), inclusion body myopathy $(12 \%)$, overlap myositis $(9 \%)$ and polymyositis $(9 \%) .2$ patients (out of 4 ) with necrotizing myopathy were treated with statins.
Clinical manifestation included muscle weakness (84\%) and skin manifestations $(48 \%)$ mainly among DM patients. 8 patients $(24 \%)$ showed interstitial lung disease (4 non-specific interstitial pneumonia, 3 usual interstitial pneumonia and 1 cryptogenic organising pneumonia), especially among patients with overlap syndrome $(n=3), D M(n=2)$ and ASS $(n=2)$. Pulmonary hypertension occurred in 7 patients (21\%), 30\% among patients with overlap myositis associated to systemic sclerosis. The rest of extramuscular manifestations are expressed in the table 1. Muscle biopsy was performed in $57 \%$ of patients ( $77 \%$ compatible with myopathy). MRI was carried out in $45 \%$ (100\% with active myositis). EMG was performed in $94 \%$ of patients with myopathic findings in $67 \%$ of them. 20 patients $(60 \%)$ presented positive antinuclear antibodies, being the most frequent antiPML-SCL (18\%), antiJo1 (18\%), antiRo (12\%) and anti-MDA5 (9\%).

All patients were treated with corticosteroids. Only 2 responded to corticosteroids in monotherapy. More than $90 \%$ needed additional immunosuppressive treatmen and $65 \%$ received 2 or more immunosuppressants. The most commonly used drugs were methotrexate $(72 \%)$, rituximab $(28 \%)$, azathioprine $(25 \%)$, immunoglobulins $(21 \%)$ and cyclophosphamide $(21 \%)$. Only in $12 \%$ treatment could be stopped because of sustained remission.

3 cases of cancer ( $9 \%$ ) were reported: myelodysplastic syndrome, lung neoplasm (in the case of paraneoplasic myositis) and lymphoma.

During the follow-up period 4 deaths were registered (12\%) due to infections and cancer.

$38 \%$ of patients required a multidisciplinary approach.

\begin{tabular}{|c|c|c|c|c|c|c|c|c|}
\hline & $\mathrm{n}$ & $\%$ & Dermatomyositis & Polymyositis & $\begin{array}{c}\text { Inclusion } \\
\text { Body } \\
\text { Mropathy }\end{array}$ & $\begin{array}{c}\text { Necrotizing } \\
\text { Myopathy }\end{array}$ & $\begin{array}{l}\text { Antisynthetase } \\
\text { syndrome }\end{array}$ & $\begin{array}{c}\text { Overlap } \\
\text { syndrome }\end{array}$ \\
\hline Raynaud & 7 & $21,2 \%$ & 2 & 0 & 0 & 1 & 2 & 2 \\
\hline Carciac Manifestations & 7 & $21,2 \%$ & 1 & 2 & 1 & 2 & 1 & 0 \\
\hline $\begin{array}{l}\text { Arrhythmia } \\
\text { Cardiomyopathy } \\
\text { Heart attack } \\
\text { Aortic stenosis }\end{array}$ & $\begin{array}{l}4 \\
1 \\
1 \\
1 \\
1\end{array}$ & $\begin{array}{l}12,2 \% \\
3 \% \\
3 \% \\
3 \%\end{array}$ & $\begin{array}{l}1 \\
0 \\
0 \\
0\end{array}$ & $\begin{array}{l}1 \\
0 \\
1 \\
0\end{array}$ & $\begin{array}{l}1 \\
0 \\
0 \\
0\end{array}$ & $\begin{array}{l}0 \\
1 \\
0 \\
1\end{array}$ & $\begin{array}{l}1 \\
0 \\
0 \\
0\end{array}$ & $\begin{array}{l}0 \\
0 \\
0 \\
0\end{array}$ \\
\hline Gastrointestinal Manifestations & 6 & $18,1 \%$ & 1 & 1 & 2 & 1 & 1 & 0 \\
\hline $\begin{array}{l}\text { Dysphagia } \\
\text { Chroric gastritis } \\
\text { Constipation }\end{array}$ & $\begin{array}{l}3 \\
2 \\
1\end{array}$ & $\begin{array}{l}9,1 \% \\
\text { \%\% } \\
3 \%\end{array}$ & $\begin{array}{l}1 \\
0 \\
0\end{array}$ & $\begin{array}{l}1 \\
0 \\
0\end{array}$ & $\begin{array}{l}0 \\
1 \\
1\end{array}$ & $\begin{array}{l}0 \\
1 \\
0\end{array}$ & $\begin{array}{l}1 \\
0 \\
0\end{array}$ & $\begin{array}{l}0 \\
0 \\
0\end{array}$ \\
\hline Severe Infections & 5 & $15,1 \%$ & 3 & 1 & 0 & 0 & 1 & 0 \\
\hline Hematologic Manifestations & 5 & $15,1 \%$ & 0 & 0 & 2 & 1 & 1 & 1 \\
\hline $\begin{array}{l}\text { Anaemia } \\
\text { Aneemia + thrombocytopenia }\end{array}$ & ${ }_{1}^{4}$ & $\begin{array}{l}12,1 \% \\
3 \%\end{array}$ & $:$ & $\stackrel{0}{0}$ & ${ }_{0}^{2}$ & $l_{0}^{1}$ & : & $\begin{array}{l}0 \\
1\end{array}$ \\
\hline Arthritis & 4 & $12,1 \%$ & 1 & 0 & 0 & 0 & 1 & 2 \\
\hline
\end{tabular}

Conclusions: Inflammatory myopathies have frequent multiorganic involvement and represent a heterogeneous group of systemic diseases as shown in our registry and in the literature. Most patients need chronically combined immunosuppres sive treatment and few achieve sustained remission. In consequence the collaboration of several specialties is necessary for the diagnosis and management of these pathologies.

\section{REFERENCE:}

[1] Nuño L, et al. Multicenter registry on inflammatory myositis from the Rheumatology Society in Madrid, Spain. Reumatol Clin 2017; 13(6):331-337

Disclosure of Interest: None declared

DOI: 10.1136/annrheumdis-2018-eular.2639

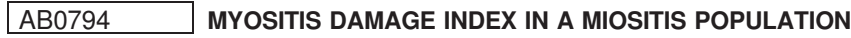 COHORT}

O. Enriquez, A. Lilia, I. Fedra, on behalf of Hospital Centro Medico Nacional 20 de Noviembre. Reumatologia, Hospital Centro Medico Nacional 20 de Noviembre, Ciudad de Mexico, Mexico

Background: Idiopathic inflammatory myopathies (IIM) are a heterogeneous and uncommon group of diseases characterised by muscular involvement and many systemic manifestations. They usually have a chronic course, and despite treat ment they often develop functional impairment. MDI-MYODAM a score to assess damage has been recently developed. Few publications in this regard have reported a prevalence of $92 \%$. There are no studies in Mexican-mestizo population describing the extent of damage and its main determinants.

Objectives: To investigate the prevalence of damage measured with the MDI MYODAM tool in patients with IIM and its relationship with characteristics of the disease and treatment

Methods: A cross-sectional study was conducted in an IIM cohort from a national reference hospital. MDI questionnaire was applied to all patients. Demographic disease characteristics, IIM subgroup (dermatomyositis, polymyositis and overlap), comorbidities (Charlson index), medical treatment were collected. Descriptive statistics were applied. Bivariate Pearson correlation test was conducted to 